\title{
Whose responsibility is it? Encouraging student engagement in the learning process
}

\author{
Alison Hood* \\ Music Department, National University of Ireland Maynooth, Maynooth, County Kildare, \\ Ireland
}

(Received 17 March 2011; final version received 6 June 2012)

This article presents the results of an action research project that focused on giving students more sense of control and responsibility over their own learning by engaging them more fully in assessment and helping them to understand the principles underpinning assessment criteria. The course is a second-year music module with approximately 85 students. I formed the class into groups to grade model answers and compiled a list of what they believed the assessment criteria should be based on this experience. I then used this list to compile a selfassessment criteria sheet, which the students filled out themselves and attached with each subsequent assessment. When I completed my analysis of data from the first cycle of action research, I implemented the learning from that cycle into a second and third cycle of action. This involved re-evaluating my initial plans in light of my findings; building on what was successful and changing what was not, and refocusing my research. The findings were significant, as their assessment results improved dramatically. Involving students throughout the assessment process, from initially setting the criteria right through to self-assessing their work, improved their grades, reduced student passivity and increased their selfconfidence.

Keywords: action research; self-assessment; group work; student learning; student confidence; deep learning

My action research question concerned how to give students more sense of control and responsibility over their own learning by engaging them more fully in assessment and helping them to understand the principles underpinning assessment criteria.

\section{Student profile and background to enquiry}

The course is an optional second-year undergraduate module in the sixteenthcentury counterpoint writing, with approximately 85 students.

This is of concern to me because I used to give weekly assignments for this course. Last year, we had a change of Head of Department who endeavoured to reduce the lecturers' workloads and encouraged us to reduce the number of assignments given. So, I changed to two marked assignments and a class test and I felt that the success rate fell. I gave them weekly assignments, but these were not graded and many did not complete these as a result. I also found myself spending a lot more time in class

\footnotetext{
*Email: Alison.Hood@nuim.ie
} 
repeating basic principles and when I received student feedback at the end of the term the better students who grasped these principles early in the course found this frustrating.

This may, however, be speculative. It might not be true that a reduction in assessment affected the grades. This could of course be caused by varied student abilities between the two years. In 2007 they had 7 assignments and I took the best 4 of these. In 2008 they only had 2 assignments. In $200722 \%$ failed or did not submit assessment. In 2008, 33\% (assignment No. 1) and 40\% (assignment No. 2) failed or did not submit assessment. By the time of the final examination, thanks to a lot of repetition in class, it seems they had caught up (although in 2007 12\% failed or did not sit the exam and in $200823 \%$ failed or did not sit the exam).

\section{Action research objective}

I really wanted to communicate the principles underpinning these assessments more quickly and efficiently so that I could reach the weaker students but also not lose the attention of the stronger students.

\section{Personal motivation}

I am committed to bringing about an improvement in my students' engagement with their music studies because I believe that all of my students have the inherent potential to do well, and that it is my responsibility to try to connect with students with different levels of learning ability. In my experience positive feedback and encouragement improves their self-confidence and permeates through every aspect of their professional and personal development. I think that involving them in assessments will go some way towards creating an environment where the students feel that they have some level of input and power over their own learning; becoming less passive and improving their sense of confidence and engagement with the subject.

This approach has much in common with The Bailey Scholars Program, which is

a learning community of scholars at Michigan State University. ${ }^{1}$ The Declaration of Bailey is that 'All members of the community work toward providing a respectful trusting environment where interdependence and personal growth are encouraged'. Their aim is 'engaged, collaborative learning that is co-created and co-designed' (Robinson, Sterner, and Johnson 2006, 2).

\section{Teaching strategy}

I began as I would have previously, with a normal weekly assessment to gather data on basic standards of the class. I then formed the class into groups and asked them to compile a list of what they believed the assessment criteria should be for the following assessments. I formed this idea after reading Alison Farrell's (2007) article 'The use of learning journals in assessment', in which she involved the students in creating the assessment criteria. Rosario Hernández (2007) has also adopted a similar approach in teaching written Spanish. She divided the class into small groups and these groups considered assessment criteria before applying them to previously written short stories. This approach to assessment has much in common with the 
Bailey Scholars who assess their work in a similar way. We would discuss these criteria at the end of the class and hopefully, through class discussion, come to agreement on a final list. This class was videoed and peer reviewed. I then used this list to compile a self-assessment criteria sheet that I posted on moodle (our virtual learning environment), which the students filled out themselves and attached with each subsequent assessment. This self-assessment relates to research carried out by the Assessment Standards Knowledge exchange based in Oxford Brookes University (henceforth referred to as ASKe). ${ }^{2}$ I considered these methods appropriate because they would involve the students in assessment and give them a sense of ownership. I hoped it would help them to grasp the main concepts more quickly. If this worked and improved their grades it might be possible to reduce the number of weekly assignments in the future.

Sources of data included assessment results, a video with peer review of the criteria selection and student feedback forms. I collected data by continuously monitoring assessment results and noting trends, and getting feedback from students about how they felt about assessment methods. I kept a personal reflective journal on the process, exploring my interactions with the students and have included relevant sections as supporting evidence in this article. My aspiration with this journal was to move beyond cognition (as simply outlining what happened) towards metacognition (by outlining and reflecting on the significance of the events outlined to a point where I could describe their significance for me, my students and for our learning) (see Bawden 2000).

\section{Social constructivism}

A social constructivist approach seems to closely reflect what I was trying to do. This is discussed in detail in an article by Rust, O'Donovan and Price (Rust et al. 2005) and in an information leaflet entitled 'Adopting a social constructivist approach to assessment in three easy steps!' published by ASKe (n.d.):

Do you believe there's more to assessment than passive transmission of standards? Would you like to actively engage your students in the assessment process? Would you like to help your students improve their learning for themselves? If so, why don't you try a social constructivist approach to assessment? (ASKe n.d.)

One of the fundamental aspects of this approach is that students must be engaged throughout the assessment process - from criteria setting to feedback (ASKe n.d.).

\section{Supporting research}

\section{Action research}

'The fundamental aim of action research is to improve practice rather than produce knowledge.' (Elliott 1991, 49)

This action research project involved constantly reflecting upon and re-evaluating my direction and activities throughout implementation. Indeed, as will be seen from my journal entry (dated 4 March 2009), my initial plan of action changed after correcting the first assignment, i.e. before the first phase of the action research had 
even taken place. In these respects it closely followed Elliot's beliefs that for successful action research:

- The general idea should be allowed to shift.

- Reconnaissance should involve analysis as well as fact-finding and should constantly recur in the spiral of activities, rather than occur only at the beginning.

- Implementation of an action step is not always easy, and one should not proceed to evaluate the effects of an action until one has monitored the extent to which it has been implemented.

(Elliott 1991, 70)

My action research project depended on a high level of collaboration from my students in the form of participation and feedback and involved peer/colleague review and discussion: 'The aim of action research is personal improvement for social transformation (...) it is essentially collaborative' (McNiff, Lomax, and Whitehead 1996, 30).

\section{Assessment, deep learning and student development}

Assessment lies at the heart of this action research project, largely due to the fundamental role it plays in encouraging deep learning and empowering students. The relationship between assessment and deep learning has been explored by many authors, as outlined in the following extracts on assessment:

The types of assessment we currently use do not promote conceptual understanding and do not encourage a deep approach to learning ... Our means of assessing them seems to do little to encourage them to adopt anything other than a strategic or mechanical approach to their studies. (Newstead 2002, 72)

Tenet 4 of the Manifesto by Price et al. (2008) explains that:

Assessment standards are socially constructed so there must be a greater emphasis on assessment and feedback processes that actively engage both staff and students in dialogue about standards. It is when learners share an understanding of academic and professional standards in an atmosphere of mutual trust that learning works best.

Tenet 5 from the same Manifesto concludes that:

Active engagement with assessment standards needs to be an integral and seamless part of course design and the learning process in order to allow students to develop their own, internalised, conceptions of standards and monitor and supervise their own learning. (Price et al. 2008)

Assessment defines what students regard as important, how they spend their time and how they come to see themselves as students and then as graduates... If you want to change student learning then change the methods of assessment (Brown Bull, and Pendlebury 1997)

\section{Research on assessment in music (self-assessment and peer assessment)}

Recent research in the area of assessment in music seems to strongly support what I am trying to achieve in my own research - both in terms of potential outcomes and 
research methodology. In 'Student-as-master? reflections on a learning innovation in popular music pedagogy', Don Lebler (2007) aims to encourage his students to become 'self-monitoring and self-directing' through a re-examination of teaching strategies and a learning-centred approach. Mike Searby and Tim Ewers (1997, 371) in their article entitled 'An evaluation of the use of peer assessment in higher education: a case study in the School of Music, Kingston University' explore the use of peer assessment within the BA in music course, concluding that 'peer assessment seems to improve students' critical faculties and gives them a greater ownership of the whole assessment process'. The word 'ownership' is one that I believe strongly reflects how my own students felt at the end of the action research process, and I think that this outcome of re-examining assessment is one that cannot be underestimated. In an article entitled 'Developing procedures for implementing peer assessment in large classes using an action research process', Roy Ballantyne, Karen Hughes, and Aliisa Mylonas (2002) researched peer assessment in a way that closely mirrored the way that I explored self-assessment, that is, within a relatively large class using action research methodology.

Both self-assessment and peer assessment seem to be particularly effective methods for encouraging performers to reflect more on their own standards of playing and to adopt more responsibility for their learning. To highlight one example from the current literature in this area, the article 'Peer assessment of tertiary music performance: opportunities for understanding performance assessment and performing through experience and self-reflection' by Diana Blom and Kim Poole (2004) explores peer assessment in a case where third-year students are asked to assess second-years. This proved quite challenging for them and opened up many more potential avenues for learning through assessment. ${ }^{3}$

\section{Potential action research questions}

(1) How do I maximise student learning while not overloading them (or myself) with assessments?

(2) How can I help students to understand the principles underpinning assessment criteria?

(3) How do I facilitate and encourage student responsibility and involvement in their own learning?

(4) How do I encourage deeper learning?

(5) How do I keep the whole class engaged and interested so that weaker students will have time and space to catch up?

(6) How can I build students' confidence and sense of control over their academic future?

Personal journal entry: 20 February 2009 (revisiting the initial AR proposallteaching philosophy)

At first I had not seen a connection between my action research project and my teaching beliefs. In my first two reflective entries, I delved into how important it was to me to 'reach' all of my students - even those who have given up on their own learning. I thought about the way to do this and focused on individual attention, responding to different types of learners. However, I think that the approach that I 
am going to adopt in my action research project is another way to do the same thing, which I find quite exciting.

\section{Personal journal entry: 20 February 2009 (How I learn/learning styles)}

I am a deep learner; I need to really understand something in order to learn and remember it. I realised that by involving the students in assessment the way I plan to, I am trying to turn the students into deep learners also. In that way they will understand the principles and criteria on a deeper level and this will help them retain the information for longer and hopefully achieve better results.

Therefore I would aspire to higher level cognition, and try to instil this desire in my students, as described by Professor Richard Bawden where he differentiates between basic cognition and higher-level cognitive processing; which he terms metacognition ('the process by which we amend the way we learn') and epistemic cognition ("gains us access to the details of our own "worldviews" and to those of others') (Bawden, n.d.). It is important not only to access our own worldviews, values and principles, but also to critique them with a view to assessing their appropriateness now and in the future.

\section{Methodology}

\section{Action research question}

Addressing all of the action research questions outlined previously was beyond the scope and time frame of my action research project. I therefore focused particularly on Question No. 3: How do I facilitate and encourage student responsibility and involvement in their own learning?

\section{Action research}

It seemed to me that the only real or practical way to explore this question was through action research, as it involves considerable experimentation and constant reevaluation. Beginning with problem identification I progressed to action planning, implementation of this plan, evaluation of results and reflection on results and process. Action research involves research 'in practice' or 'in doing', and thereby very much mirrors how I tried to encourage and instil student learning; by involving them 'in doing' through compiling assessment criteria, working as part of a group and selfassessing their work.

\section{Assessment and group work}

In order to answer this question, I focused on how we assess students and how they respond to that assessment. I tried to involve them throughout the assessment process from forming assessment criteria through to self-assessing their work. I used group work to encourage the students to explore potential assessment criteria. 


\section{Triangulation of evidenceldata collection}

I monitored the success of the project through recording and collecting various kinds of data. This included: detailed personal analysis of trends in assessment results; a video and peer review of the class that implemented the first cycle of action research; regular analysis and reflection on student feedback forms/questionnaires (including both written and verbal comments); and capturing my thoughts using a personal journal that reflects on the above data. As we progressed through the action research project, I also noted a higher level of student engagement (questions/comments, etc.) in class.

\section{The next step}

When I completed my analysis of data from the first cycle of action research, I implemented the learning from that cycle in second and third cycles of action. This involved re-evaluating my initial plans in light of my findings; building on what was successful and changing what was not, and refocusing my research.

\section{Collecting data before the first cycle}

Personal journal entry: 4 March 2009: reconsideration of group work on criteria following first assignment

Having corrected the first assignment, I reviewed my plan to ask them to work in groups and arrive at assessment criteria based on the basic principles. I now think I should give them two sample answers including typical mistakes and ask them to correct them in groups (and to suggest a grade). I will then ask them to compile a checklist of things to avoid or watch out for as well as a list of things that make a good assignment based on this experience. We can then use these lists as the basis for our criteria and self-assessment sheet.

The reason I am making this change is that I think it will be better for them to see the criteria applied 'in action'/practice rather than 'in theory'/simply focusing on the principles.

\section{Personal journal entry: 6 March 2009: reflection on class on 5 March}

I was disappointed with their first assignments. A lot of the students had missed the main points and misunderstood the principles. Instead of handing back their assignments (as I did not have time to correct all of them by the class - one of the reasons for the recent reduction in assignments), I looked through them and noted common errors. I then compiled these onto a handout and went over these common errors in class. I then worked through some examples with them on the whiteboard and gave them examples to do in class based on these. I invited questions one-on-one and the questions were continuous. I even had to curtail them at the end, as the class was running over time. In the previous class no one had asked questions so I was delighted with this result. At the end of the class I asked for a show of hands as to who felt clearer on the subject at the end of this class compared with the beginning and nearly everyone (I would estimate $90 \%$ ) raised their hands. I am looking forward to receiving their next (second) assignment to see if this will show in their grades. 
I was delighted with this, as I was disappointed I had not managed to correct all of their assignments before class. As it turned out, I think the class was even more effective as a result. This unknown/surprise aspect of action research is one that has the potential to be disconcerting at the outset but is in fact leading my research in very beneficial ways. Even though the initial result of their assignments was disappointing, as was the fact that I did not have time to correct all of their assignments in advance of the next class, these 'negative' contributions influenced and informed my next step and ultimately changed things for the better.

Personal journal entry: 7 March 2009: thoughts following corrections of first assignment

$34.5 \%$ did not submit the first assignment. This is worse than last year with a total for this first assignment of $46.5 \%$ having failed or not submitted. Obviously I need to be very careful with this class. I think that I might circulate an anonymous questionnaire asking:

(1) if they submitted the first assignment: Yes/No

(2) if No, why not? (unsure if it was worth doing for the credit, unsure I would be able to do it properly, other reason - please state)

(3) if Yes, did you find it (easy, average, difficult)?

(4) if you found it difficult do you think you understand it better following the feedback and practice in class?

(5) What could be done to improve your learning even further?

Personal journal entry: 25 March 2009: thoughts following corrections of second assignment

Twelve (14\%) students obtained firsts compared with $7(8 \%)$ for the first assignment; meaning that the number of students who received a first class has nearly doubled; 14 $(16.5 \%)$ got 2 is compared with $8(9.5 \%)$ for the first assignment; meaning that the number of students who received a $2 \mathrm{i}$ has also nearly doubled; $22(26 \%)$ got $2 \mathrm{iis}$ compared with $16(19 \%)$ for the first assignment.

There was a significant fall in the number of students who failed; the total was 3 $(3.5 \%)$ compared with $10(12 \%)$ for the first assignment; so the failure rate has reduced by two thirds.

I was delighted with these results as they show significant improvement. However, I am concerned about the number of students who are not submitting assignments. Twenty-seven students (32\%) did not submit the second assignment - only marginally down from the first assignment.

Thoughts on this: it could stem from a lack of confidence, failure to come to class or not considering the assignment worth sufficient credit. It could also be influenced by the fact that I have told them I will be taking their best 4 out of 5 marks; so missing one would not substantially affect their overall assessment mark. However, 18 out of 26 students have not submitted either of the first two assignments. 
The first cycle of my action research will be implemented in class tomorrow and will be based on assessment work and criteria and I hope that might help to resolve any outstanding issues. If the submission rate for the next assignment is still as low, I will try to delve deeper.

\section{Findings, results and analysis}

\section{First cycle of action research}

Putting the research plan into action: video class 26 March 2009

This class introduces the concept of imitation to two-part counterpoint exercises building on work they have already been doing (without using imitation).

After introducing the new element, I gave them two sample answers including typical mistakes and asked them to correct them in groups (and to suggest a grade). I then asked them to compile a checklist of things to avoid or watch out for as well as a list of things that make a good assignment based on this experience. We then used these lists as the basis for our criteria and self-assessment sheet, which they used for their next assignment.

The reason I did this stemmed from my belief that it would be better for them to experience the criteria applied 'in action' (in practice) rather than 'in theory' (simply focusing on the rules), and I hoped it would improve their grades as a result.

The potential positive outcomes for the students that I hoped may arise from this included building their self-confidence and enabling them to become more selfcritical. It is also socially beneficial to work in groups and helps to prepare the students for future employment.

This class was observed by one of my colleagues who acted as a peer reviewer and critical friend throughout this process. I found that these comments and the subsequent discussion of my teaching were extremely helpful. This critical friend would often verbalise what I thought were positives and negatives about my own approach. In general I found that undertaking action research into my teaching opened up dialogue with my colleagues in a way that is currently enriching all of our teaching.

29 March 2009: student feedback statistics following video class 26 March 2009

Question 1: I found this class helped me towards learning and understanding the subject

Question 2: This class helped clarify problems and build my confidence for approaching assignments

Question 3: I would like the lecturer to adopt more of this kind of approach in lectures in this module

Question 4: I enjoyed taking part in the group work during this class 
A total of 47 forms were submitted:

\begin{tabular}{lccc}
\hline & Agree & Neutral & Disagree \\
\hline Question 1 & 45 & 2 & 0 \\
Question 2 & 43 & 4 & 0 \\
Question 3 & 45 & 2 & 0 \\
Question 4 & 41 & 3 & 3 \\
\hline
\end{tabular}

Note: I think that the three students who disagreed with Question 4 may have responded in error as I had mistakenly reversed the order of responses in the final question and their additional comments about the group work were positive.

Examples of student comments following video class

'The group task helped me to see where I was making mistakes in my own work'.

'By giving out examples it helped me think critically for future assignments'.

'Inspired a more in-depth study of our own work including the introduction of self-criticism'.

'Found if productive and helped me in understanding where I would go wrong'.

'Extremely helpful in understanding what is looked for from the assignment work'.

Found this class v. helpful and it really helped me think critically when doing an assignment'.

'The idea of self-assessment has helped me understand what I should be including or avoiding to a much greater extent. If more lecturers e.g., "Baroque Counterpoint" or other similar classes adopted this method I feel it would be of great benefit to students'.

'Class interaction was good, made me think about and hence remember mistakes in composition rather than just being told'.

'This class seriously helped me understand many parts of this module that I did not understand'.

'Class was really really helpful. Group work gave everyone a chance to build on what they already knew and clarify any doubts with other students. Thanks Alison'.

'It helped me see how assignments are marked. Better understanding of counterpoint'.

'We were able to understand why the lecturers mark so hard. That was fun'.

'It is a great way of looking at one's own work more critically. Also discussing positive and negative aspects of the writing style has taught me more about what to write and what to avoid when writing'. 
'This is a good method of learning new material and I feel more confident in my approach to assignments now'.

'Was really helpful. Looking at examples is really good because you realise how much you know by looking at them'.

\section{Personal journal entry: 29 March: reflection following video class}

I was really pleased with the timing of this class, as I had been concerned that the group work and feedback would take longer than I had scheduled. There were a lot of questions from students - both within the lecture-type sections of the class and in the group work. They paid attention and demonstrated enthusiasm and interest in the subject and in the group work. I directed them a little with cues to help group discussion.

I was pleased with the overall student learning in this session. I thought the pacing of the class plan was just right (even though I had reservations about this beforehand). Use of powerpoint, handouts and the whiteboard helps to communicate with different types of learners. The biggest surprise to me was how much they enjoyed the group work. If it is possible to introduce more enjoyment into the learning process, this might increase attendance rates and ultimately improve grades. There was a high level of interaction and discussion evident.

\section{Points of good practice}

- Group work went really well and they enjoyed it.

- High level of student interaction and participation.

- Positive feedback from students.

- Demonstrated real learning and understanding.

- Fulfilled learning outcomes.

\section{Suggestions for areas of improvement and how improvements could be made}

Group work feedback could be more organised making use of the designated spokesperson. This will avoid situations where stronger students monopolise the discussion and will give everyone a chance to feedback to me. My colleague and peer reviewer, who uses a lot of group work in his lectures, also noted this point.

\section{Reflection on planning}

I thought it was very interesting that the group feedback discussion took a direction that I had not foreseen, into negative and positive marking and grading. I thought this was very beneficial and gave the students more of an insight into how we mark. What I learned from this was that it is sometimes good to relinquish control slightly, as it reveals what they really want to discuss and learn.

\section{Reflection on students' learning experience and future action steps (particularly in light of observer's comments)}

Group work: I will manage the feedback so that each group has a chance to give their opinions. 
I will make sure that students' attention is focused on one thing at a time (by giving assignments back ahead of the start of class).

I will incorporate more group work into future lectures and will try to include self-assessment in other modules.

Personal journal entry: 1 April 2009: thoughts following corrections of third assignment (this is their first assignment following the implementation of my action research plan and video class)

Positive: I am delighted with the number of firsts (21 in total; 8 of these receiving $100 \%$ for perfect answers). Therefore, $25 \%$ of students received a first in this assignment. This percentage is three times higher than the percentage receiving firsts in the first assignment. Eighteen percent received a $2 \mathrm{i}$ and $18 \%$ received a $2 \mathrm{ii}$ and only 2 students failed. Interestingly some students noticed their mistakes and highlighted them in filling out the self-assessment sheet but did not change them. This might be because they are too honest or because they are unsure of how to change them.

Negative: the submission rate is still low: $32 \%$ of students registered for the module did not submit this assignment and 15 students have not submitted any assignment so far. It seems that my approach has been successful in increasing the grades of those students who are submitting work but not in increasing the submission rate.

Action I am going to take to try to remedy this: I am going to hand out a questionnaire tomorrow based on the questionnaire I was going to circulate following the first assignment.

\section{Second cycle of action research}

I noticed some mistakes that students made that were not covered by the assessment criteria/checklist so I asked them to review their assignments and feedback to me in class with any of these that they found. I then added these to the checklist for the next assignment, posting it on moodle and requested them to fill these out and attach them to their next submission.

Personal journal entry: 8 April 2009: reflection on student feedback from class 2 April 2009

A total of 41 feedback forms were submitted:

(1) How many assignments have you submitted?

\begin{tabular}{llll}
\hline Assignments submitted & 1 & 2 & 3 \\
\hline No. of students & 3 & 8 & 30 \\
\hline
\end{tabular}


(2) If you have submitted two or less why was this?

\begin{tabular}{lccc}
\hline Reasons for non-submission & Not worth credit & Lack of confidence & Other \\
\hline No. of students & 0 & 1 & 10 \\
\hline
\end{tabular}

Only one student said that they did not submit due to lack of confidence in their ability to do them properly. The other reasons were all due to absence.

(3) Are you generally finding the assignments

\begin{tabular}{lccc}
\hline Ease of assignments & Easy? & Average? & Difficult? \\
\hline No. of students & 6 & 28 & 7 \\
\hline
\end{tabular}

Note: All seven students who answered that they found the assignments difficult believe they are improving, choosing Yes or Somewhat for Question 4.

(4) Do you feel you are improving as the course progresses?

\begin{tabular}{lccc}
\hline General improvement & Yes & No & Somewhat \\
\hline No. of students & 31 & 0 & 10 \\
\hline
\end{tabular}

I am delighted with this, as all students who filled in this form feel they are improving to some extent through the module.

(5) If you found it difficult at the beginning, do you think you understand it better following the feedback and practice in class?

\begin{tabular}{lcc}
\hline Class feedback and practice & Yes & No \\
\hline No. of students & 41 & 0 \\
\hline
\end{tabular}

I am very happy to see that my approach seems to be benefiting all of the students who have responded.

(6) Did you find filling out the self-assessment sheet helpful?

\begin{tabular}{lcc}
\hline Self-assessment sheets & Yes & No \\
\hline No. of students & 41 & 0 \\
\hline
\end{tabular}

Judging from the grade averages and feedback in class I thought that the response to this question would be positive but I am really thrilled with this outcome, as this involvement in assessment forms the basis for my action research project. 
(7) What could be done to improve your learning even further?

I received the following responses:

4 students requested more examples

6 students requested more/larger assignments

4 students requested more practice

2 students requested more use of the checklist

2 students requested more group work

On group work: 'Others' strengths help other people in the group'

'Other modules could be adjusted to mirror this one'

'I think the teaching method is very helpful. I don't feel like I need to go over things because we repeat a lot in class and it goes into my head easier'.

'Make things a little bit harder/challenging. Since there are written questions in the exam, one of the assignments should mimic these in preparation'.

\section{Plan for third cycle of action research}

As most of the exam focused on imitative counterpoint, I had been concentrating more on that. However, the comment above (in italics) about the written part of the exam was well founded. In the next class I planned to incorporate group work and begin a third cycle of action research by using a similar approach to developing selfassessment criteria but now in relation to these written (essay-type) exam questions.

Personal journal entry: 8 April 2009: thoughts following corrections of fourth assignment following addition of missing elements to self-assessment sheets (second cycle of research)

Thirty-one students obtained a first class with 18 receiving $100 \%$. This is an incredible statistic; I have not seen the number of high firsts even come close to this since beginning the course 6 years ago. One student failed (compared with 10 for the first assignment); so the number of students at the lower end of marks has significantly reduced.

Twenty-four students did not submit and 14 have not submitted any of the 4 assignments. I feel the feedback form ( 2 April) did not address this and I now think that perhaps it is due to the fact that most of the students who do not submit assignments are not attending class. I might take a roll during the next class to check if my assumption is correct.

Three students told me they wished other lecturers would adopt the selfassessment sheets, as they found them invaluable for understanding where they were making mistakes and they were then able to correct them in advance of submission. One student told me she has doubled her grade as a result of this approach. Another student with learning difficulties has told me she is finding them extremely helpful, as she needs more time to process new ideas and she can go through the checklist in her own time. Her grade has risen from a fail to a $2 \mathrm{i}$. 
Personal journal entry: 19 April 2009: reflection following attendance roll for class on 9 April

Total students: 43

- 13 of the 14 who have not submitted any assignments so far did not attend this class.

- 14 of the 18 who received $100 \%$ in their last assignment attended this class.

So my theory may be correct; that most of the students who do not submit assignments are not attending class: I am going to take another attendance roll in the next class and will do so in the future.

Personal journal entry: 26 April 2009: reflection following attendance roll for class on 23 April

Total students: 51

- This is a significant increase on 9 April and may be due to the fact that we are approaching the end of the semester.

- 13 of the 14 who have not submitted any assignments so far did not attend this class.

Personal journal entry: 26 April 2009: thoughts following correction of fifth and final assignment

Twenty-seven students (32\%) obtained a first class. This represents a slight reduction compared with the last assignment but could be possibly be explained by an increased element of complacency on the students' part due to the very high results last week. However, the results are still significantly above average. Twelve students received a $2 \mathrm{i}$ and 15 received a $2 \mathrm{ii}$. Three students failed and 23 did not submit.

Personal journal entry: 26 April 2009: reflection following attendance roll for class on 30 April

Total students: 52

- This represents a slight increase on last week. However, I would expect high attendance for this class, as it is the final class of the semester.

- All 14 students who have not submitted any assignments were absent for this class.

Note following exam: 10 of the 14 students who did not submit any assignments were absent from the exam. Only two of these had deregistered. 


\section{Third cycle of action research}

In the class on 23 April 2009, I divided the class into groups of 4-5 students and gave them sample essay-type exam questions. I decided on this action based on student feedback that they wanted more practice on these kind of questions and because I wanted to see if adopting the same approach to developing assessment criteria might work on essay-type exam questions. I gave four topics: Palestrina; Palestrina's use of dissonance; Nota cambiata; and Paraphrase Mass. The assignment was 'Write short notes (up to a maximum of one page each) on (for example) the Paraphrase Mass giving musical examples or referring in your text to particular pieces of music as appropriate'. I asked them to compile a checklist of topics to discuss or include that they would look for if they were correcting such an exam question in order to establish a list of assessment criteria.

There were a few groups working on each topic. I then asked them to assign a spokesperson that would put all of the group's ideas onto one sheet and feedback to the class. We then compared answers with the other groups that worked on the same topic. I felt that it was a lot more organised in terms of feedback as, acting on discussion with my peer reviewer/critical friend, I followed through with a spokesperson this time. In the first cycle of action research I had allowed a general discussion to develop, which resulted in more outspoken students tending to monopolise the discussion and not every group got a chance to feedback.

At the end of the class I asked for each spokesperson to hand up their sheet and I compiled their answers onto four files and posted these on moodle. I hoped it would provide a good study guide and focus their attention on exam preparation. I also hoped it would increase their confidence in that they would feel more prepared and know what I might be looking for in answers to exam questions.

I handed out a feedback form in the class of 30 April, which tried to ascertain if my aspirations for this third cycle of action research were well founded. I also asked for some general feedback in this form, which I might then be able to use to make suggestions for change, not just within my future modules but also at departmental level.

Personal journal entry: 2 May 2009: thoughts following student feedback in last class 30 April (third cycle)

A total of 49 feedback forms were submitted.

Question 1: I found that I learned more from working within the group than if I had filled out the form on essay-type questions myself.

\begin{tabular}{lccc}
\hline & Agree & Neutral & Disagree \\
\hline No. of students & 42 & 3 & 1 \\
\hline
\end{tabular}

This is a very positive response and reflects the students' feelings that group work was very helpful. Three students responded NA (possibly not present for the class in question). 
Question 2: This class helped to clarify what is expected in essay-type answers and to build my confidence for approaching the exam.

\begin{tabular}{lccc}
\hline & Agree & Neutral & Disagree \\
\hline No. of students & 44 & 2 & 1 \\
\hline
\end{tabular}

I am very happy with this, as it seems I have addressed the issue that arose previously of insufficient preparation for the essay-type questions in the exam. Two students responded NA.

Question 3: I found that developing assessment criteria within groups and applying self-assessment to my work helped my learning and improved my confidence in the subject.

\begin{tabular}{lccc}
\hline & Agree & Neutral & Disagree \\
\hline No. of students & 47 & 0 & 1 \\
\hline
\end{tabular}

This question has the highest number of positive responses and, I think, reflects their feelings towards self-assessment. One student responded NA.

Question 4: I think it would help my learning if this kind of approach were adopted in other modules.

\begin{tabular}{lccc}
\hline & Agree & Neutral & Disagree \\
\hline No. of students & 44 & 3 & 1 \\
\hline
\end{tabular}

I am particularly interested in this response, as the high number of positive responses could possibly be used to encourage the implementation of new kinds of approaches to assessment within our department. One student responded NA.

Question 5: Any other comments.

The following are examples of the responses received:

The student who responded 'Disagree' to questions 1 and 3 wrote: 'I'm not a fan of group work in general but I can see how others would like it. I think it's good for students who are not sure or confident about their academic abilities or how to approach a subject. In general I fill it panders to this lack of initiative, and personally find it frustrating'.

'I really think it would be beneficial for other lecturers to take on this approach, particularly in subjects such as counterpoint, fugue, etc. This is one of the only lectures I feel I know exactly what is expected with no ambiguity'. 
'Group work was really really helpful. You learn a lot by listening to others. The group work for the essay questions was very helpful. I think group work is a great idea for every module'.

'It is a very good idea to get everyone to write what they know and then compile the knowledge and sharing it with everybody. This should definitely be done in all modules'.

'Learned most in group class as was not afraid to ask stupid questions'.

'I found last week's class extremely helpful for showing us what is expected in the exam. I feel this will aid me in my studying to a great extent'.

'Group work was worthwhile but very time consuming'.

'I found that once I knew exactly what was expected from me with the self assessment sheet, I found that my marks were improving every week. I think if it was brought into all modules it would be great'.

\section{Reflection on the comments above}

I think that the first comment above is something that I will try to address in future group work, as I do not want to lose the attention of the stronger students. Indeed I feel I can personally relate to the issue raised by this student, as I myself have not enjoyed group work in the past for similar reasons. However, more recent involvement in group work, both as a student and as a teacher, has opened my eyes to its inherent potential learning opportunities. The answer may lie in organising the groups more carefully, but I will have to do more research in order to address this issue.

A lot of these comments focus on the desire for other modules to adopt a similar approach and I will present my findings and discuss this with my colleagues to explore possibilities for the future. Some responses requested more use of moodle for assessment (in cases of missing class). I will make sure to post all assessments on moodle in future in order to address this.

\section{Action implications or recommendations}

\section{Response to my initial reservations}

My initial reservations were that class time might be too limited to work in so many groups and collect feedback, and that students might be reluctant to work in groups, as they are not used to it. These reservations both proved to be unfounded. Although there were one or two negative comments from students regarding group work, on the whole students found it very enjoyable and extremely beneficial. The allocation of time in class to group work did not reduce the content I was able to cover; in fact I believe it significantly increased how much and how deeply they learned. It will ultimately enable me to cover even more content in future. 


\section{Implications for students' learning}

Positive outcomes

- There was a significant increase in grades across the board.

- There was an increase in engagement and participation in class.

- Classes were more fun and enjoyable.

- Students seemed to gain confidence in their abilities and in relation to the exam.

- Students became more self-critical.

- They seemed to learn at a deeper level and retain the information for longer.

- I found I did not have to repeat myself so much in class.

- Group work and increased responsibility is socially beneficial and practical for future work environments.

\section{Unexpected (and positive) outcomes}

- The level of enjoyment that students gained from group work.

- How much they learned from other students.

- How much they appreciated being given more responsibility.

- How much they appreciated specific learning outcomes and detailed lesson plans.

- Relinquishing some control on my part can lead to unforeseen and worthwhile discussion.

- The use of self-assessment sheets seemed to be particularly beneficial to those students with learning difficulties, as it gave them more time and control over their work.

- I will incorporate more group work and interaction into other modules.

- I will incorporate self-assessment into other modules.

- I will make intended learning outcomes more explicit for the students.

- I will design detailed lesson plans including teacher activities and student activities.

Other issues still to be addressed

- Non-attendance.

- Non-submission of assignments.

- I think that the relationship between failure or non-submission rates and attendance could be investigated further.

- Stronger students who may feel that they are 'carrying' the weaker students in group work and that they could be challenged more. 


\section{Assessment load}

The students did five assignments this year, which is an increase on last year. However, it is still significantly fewer than the weekly assignments they used to do in this course. It may even be possible with this approach to reduce the assessment load to four assignments or even implement selective marking of two chosen assignments and give generic feedback on the others (particularly in light of the positive results obtained by giving generic feedback on the first assignment).

\section{Further steps for the future}

Given, the high percentage of first-class results, I could progress further in this course next time, thereby raising the standard. This would also address some of the feedback from stronger students that it could be made more challenging.

\section{Reflection}

I found that undertaking this action research project significantly advanced my understanding of the learning process and most certainly improved my practice. It also made me look more closely at how I myself learn and acknowledge my own values and educational background. I found that I was attempting to encourage deeper learning in a way that mirrored the way that I learn best. As I mentioned previously, my approach is driven by my personal belief that all students have the inherent potential to do well and that different students learn in different ways.

I was delighted by the response of the students in general to this project. They seemed to flourish by being more involved in the learning and assessment process and by being let into this 'inner circle'. They also seemed to appreciate being given a greater degree of responsibility for their own learning.

I learned not to shy away from greater class interaction and group work; that more content can be communicated more effectively by their implementation. I also found that writing up these findings in a more personal and reflective way was very refreshing and seemed to help me to get to the root of issues more directly.

Lecturing alone is extremely limited in its potential to reach students. Adopting a social constructivist approach to teaching with a less formal and more interactive class environment encourages students to ask questions and to interact with each other in a much more enjoyable atmosphere; one that promotes deeper learning and engagement with the subject. Involving students throughout the assessment process, from initially setting the criteria right through to self-assessing their work, reduces student passivity and increases their self-confidence. This increased confidence has the potential to influence other aspects of their personal and professional lives, giving them an increased sense of ownership and control over their academic future.

\section{Notes}

1. With thanks to Dr Seamus Lillis who alerted me to the similarity between their approach and mine.

2. Further information on the work carried out by ASKe can be found at http://www.brookes. ac.uk/aske 
3. Other research into assessment in the area of performance has been carried out by Desmond Hunter (1999) at the University of Ulster in 'Developing peer-learning programmes in music: group presentations and peer assessment', Martin J. Bergee and Lecia Cecconi-Roberts (2002) in 'Effects of Small-Group Peer Interaction on SelfEvaluation of Music Performance' and Ryan Daniel (2004) in 'Peer assessment in musical performance: the development, trial and evaluation of a methodology for the Australian tertiary environment'.

\section{Notes on contributor}

Alison Hood is a first-class honours graduate of Trinity College Dublin. Her research interests lie in the area of analysis and performance, particularly in piano music from the nineteenth century, and research into teaching and learning. She graduated from Trinity with a $\mathrm{PhD}$ entitled 'Chopin's Strategic Integration of Rhythm and Pitch: a Schenkerian Perspective'. During her time at Trinity she was awarded the Taylor Entrance Exhibition (1992), the Home Hewson Scholarship (1996), the Trinity College Postgraduate Award (1999) and the Government of Ireland Scholarship (1999). She was elected Scholar of Trinity in 1994. She lectured part-time in Trinity from 1997 to 2003 and was appointed as visiting lecturer at the University of Oregon for the autumn term of 2001. She began lecturing in the National University of Ireland, Maynooth in 2003. Alison is a pianist and cellist engaged in both classical and popular performing and recording. Her debut album of John Field's music was released by RCA Victor, New York, in 1999. Alison's presentations and publications reflect her interests in musical analysis and performance. Alison is a member of the All Ireland Society for Higher Education (AISHE) Special Interest Group on Action Research (2009-Present) and the NUI Maynooth Project on Large Group teaching (2009-Present). She was nominated NUI Maynooth Music Department Learning Outcomes Fellow in 2009 and has a Postgraduate Diploma in Higher Education (2009) from NUI Maynooth.

Her recent publications include:

Structural coupling in the coda of Chopin's barcarolle. In Chopin 1810-2010: IdeasInterpretations - Influence, ed. Artur Szklener. Warsaw, forthcoming.

Engaging students in the assessment process in large groups. In Large group teaching. Centre for Teaching and Learning, NUI Maynooth, 2011.

Intraopus connections in Chopin's nocturnes opus 27. In The sources of Chopin's creative style: Inspirations and context, ed. Artur Szklener. Warsaw: Narodowy Instytut Fryderyka Chopina, 2010.

Objectifs et réalisation compositionnels dans la Barcarolle de Chopin: une forte cohérence structurelle et un défi pour l'interprétation. In Analyse musicale, 2010.

Tonal and rhythmic hidden repetition in Chopin's prelude opus 28 No.14. In Chopin in Paris: The 1830's, ed. Artur Szklener. Warsaw: Narodowy Instytut Fryderyka Chopina, 2007.

\section{References}

Assessment Standards Knowledge exchange (ASKe). Centre of Excellence in Teaching and Learning (CETL) Resources. n.d. '1,2,3' leaflets: Adopting a social constructivist approach to assessment in three easy steps. http://www.brookes.ac.uk/aske/documents/SocialConst. pdf

Ballantyne, R., K. Hughes, and A. Mylonas. 2002. Developing procedures for implementing peer assessment in large classes using an action research process. Assessment \& Evaluation in Higher Education 27, no. 5: 427-41. 
Bawden, R.J. n.d. An atlas of conceptual maps. http://www.learningtolearn.sa.edu.au/ Colleagues/files/links/3C2_R3_Atlas.pdf

Bawden, R.J. 2000. Valuing the epistemic in the search for betterment: The nature and role of critical learning systems. Cybernetics and Human Knowing 7, no. 4: 5-25.

Bergee, M., and L. Cecconi-Roberts. 2002. Effects of small-group peer interaction on selfevaluation of music performance. Journal of Research in Music Education 50, no. 3: 256-68.

Blom, D., and K. Poole. 2004. Peer assessment of tertiary music performance: Opportunities for understanding performance assessment and performing through experience and selfreflection. British Journal of Music Education 21: 111-25.

Brown, G., J. Bull, and M. Pendlebury. 1997. Assessing student learning in higher education. London: Routledge.

Elliott, J. 1991. Action research for educational change. Milton Keynes, Philadelphia: Open University Press.

Farrell, A. 2007/1. The use of learning journals in assessment. In Case studies of good practices in assessment of student learning in higher education, ed. G. O'Neill, S. Huntley-Moore and P. Race, 99-103. Dublin: AISHE Readings.

Hernández, R. 2007. Using peer and self-assessment practices to assess written tasks. In Case studies of good practices in assessment of student learning in higher education, ed. G. O'Neill, S. Huntley-Moore and P. Race, 85-9. Dublin: AISHE Readings.

Hunter, D. 1999. Developing peer-learning programmes in music: Group presentations and peer assessment. British Journal of Music Education 16: 51-63.

Jordan, S. 1999. Self- and peer assessment. In Assessment matters in higher education, ed. S. Brown and A. Glasner, 172-82. London: Society for Research into Higher Education and Open University Press.

Lebler, D. 2007. Reflections on a learning innovation in popular music pedagogy. International Journal of Music Education 25, no. 3: 205-21.

McNiff, J., P. Lomax, and J. Whitehead. 1996. You and your action research project. London \& New York: Hyde Publications.

Newstead, S. 2002. Examining the examiners: Why are we so bad at assessing students? Psychology Learning and Teaching 2, no. 2: 70-5.

Price, M., B. O’Donovan, C. Rust, and J. Carroll. 2008. Assessment standards: A manifesto for change. Brookes eJournal of Teaching and Learning 2, no. 3.

Robinson, C., G. Sterner, and T. Johnson. 2006. Don't build it and they will come: Creating space for wholeness, meaning, and purpose in higher education. Journal of College and Character 7, no. 6: 1-4.

Ryan, D. 2004. Peer assessment in musical performance: The development, trial and evaluation of a methodology for the Australian tertiary environment. British Journal of Music Education 21: 89-110.

Rust, C., B. O'Donovan, and M. Price. 2005. A social constructivist assessment process model: How the research literature shows us this could be best practice. Assessment and Evaluation in Higher Education 30, no. 3: 233-41.

Searby, M., and Tim Ewers. 1997. An evaluation of the use of peer assessment in higher education: a case study in the School of Music, Kingston University. Assessment and Evaluation in Higher Education 22, no. 4: 371-83. 